\title{
Assessing cost-effectiveness with equity of a programme targeting marginalised girls in secondary schools in Tanzania
}

Ricardo Sabates*, Pauline Rose, Benjamin Alcott and Marcos Delprato

August 2020

Ricardo Sabates (* Corresponding author)

University of Cambridge, Faculty of Education, 184 Hills Road, Cambridge.

Rs867@cam.ac.uk

ORCID: 0000-0002-1433-5667

Twitter: @RSabates72

Pauline Rose

University of Cambridge, Faculty of Education, 184 Hills Road, Cambridge.

ORCID: 0000-0002-6701-6774

Twitter: @PaulineMRose

Benjamin Alcott ${ }^{1}$

University of Cambridge, Faculty of Education, 184 Hills Road, Cambridge.

ORCID: 0000-0002-2087-7964

Marcos Delprato ${ }^{2}$

University of Cambridge, Faculty of Education, 184 Hills Road, Cambridge.

ORCID: 0000-0001-9333-8331

Twitter: @DelpratoM

${ }^{1}$ University College London, Institute of Education, WC1H OAL, London

${ }^{2}$ University of Sussex, Department of Education, Falmer, BN1 9RH, Sussex. 
Biographical note:

Ricardo Sabates is Professor of Education and International Development and member of the Research for Equitable Access and Learning (REAL) Centre at the Faculty of Education, University of Cambridge. He achieved his doctoral degree in development studies at the University of Wisconsin-Madison. His research interests include social outcomes of learning, understanding the role of education over the lifecourse for marginalised populations, impact evaluation and cost-effectiveness analyses.

Pauline Rose is Professor of International Education and Director of the Research for Equitable Access and Learning (REAL) Centre at the Faculty of Education, University of Cambridge. Her research focuses on understanding and tackling barriers to inequalities in education, including attention to education financing. She has extensive experience of working with research teams, policy actors and practitioners in sub-Saharan Africa and South Asia.

Benjamin Alcott is a Lecturer at the UCL Institute of Education. He received his doctoral degree, in education policy, from the University of Michigan. His research interests include early years education policy in South Asia and sub-Saharan Africa, inequities in learning, and the economics of education.

Marcos Delprato is a Lecturer in International Education at the Centre for International Education (CIE), University of Sussex. He has a broad experience in the application of quantitative methods in international education and development. His research aims to highlight education inequalities from low-income countries for an array of issues ranging from early marriage and schooling outcomes, wealth, and the intergenerational transmission of education from marginalised groups. 


\begin{abstract}
Cost-effectiveness studies rarely pay explicit attention to whether resources are used effectively to benefit the most marginalised. By linking a quasi-experimental design with detailed financial information, we analyse the cost-effectiveness of a programme targeting the most marginalised girls in government secondary schools in deprived rural areas in Tanzania by the non-governmental organisation, the Campaign for Female Education (CAMFED). Our methodology is novel in its approach to taking equity into account. We find the costeffectiveness ratio for CAMFED's programme to be similar to interventions designed for more advantaged populations who are easier (and less costly) to reach. One key policy implication from our findings is that it is important to recognise that it may cost more to reach the most marginalised girls; however, interventions targeting these girls can also be cost-effective where they achieve a large and significant impact, as is the case with CAMFED's programme. A second policy lesson is that a programme targeting the most marginalised can have wider benefits: in our analysis, we find that learning also improves for other girls as well as boys in CAMFED-supported schools.
\end{abstract}

Keywords: Cost Effectiveness, Equity, Girls’ Education, Tanzania 


\section{Acknowledgements}

This project was funded by Echnida Giving and DFID's Girls' Education Challenge (via the Campaign for Female Education, CAMFED). The authors are extremely grateful for the immense support provided by CAMFED in preparing this paper, in particular Lucy Lake, Stuart Johnson, Luxon Shumba, Anthony Peckham and Jose Liht. We appreciate their engagement in the process, including their openness with sharing data on detailed costs of their programme, and providing on-going advice and feedback. Comments on previous versions of this paper were provided by Dr Monazza Aslam, Dr Shenila Rawal and Professor Anna Vignoles. The analysis and arguments in the paper, as well as any errors, are the responsibility of the authors of the paper. 


\section{Introduction}

Cost-effectiveness analysis, which provides information on how much it costs to achieve a given impact, is an important tool for policymakers in choosing which reforms to fund in international development settings (see, for example, DFID 2011). The vast majority of studies on cost-effectiveness undertaken to date in international development settings have been in the health sector (Masset et al. 2018). In contrast, a recent comprehensive systematic review concludes that very few studies on the impact of educational interventions include costeffectiveness analysis (Snilstveit et al. 2016).

While there has been a growing education evidence-base in recent years using experimental and quasi-experimental approaches providing information on impact, most of these have not been accompanied by data on cost (McEwan 2015). Thanks to a large extent to the work of Abdul Latif Jameel Poverty Action Lab (J-PAL), this is beginning to change (Dhaliwal et al. 2013; McEwan 2012, 2015; Uneze and Tajudeen 2013; Evans and Popova 2016; Levin and Belfield 2015). For example, Dhaliwal et al. (2013) reviewed 11 education programmes in six countries, all of which used randomised evaluations and costs data to enable cost-effectiveness analyses.

In both education and international development, studies do not usually account for the differential impact and costs for different population groups. Yet, it is likely that children who are most marginalised, for example due to poverty, gender, disability or where they live, require more support and resources to keep them in school and to learn once there. As such, there is a need for analysis to pay explicit attention to whether and how resources can be most effectively used to benefit the most marginalised children, as well as to pay attention to whether reaching them can also benefit others in their schools. There may be a potential trade-off faced by policymakers and decisionmakers between equity and efficiency in the light of budgetary constraints. Notably, reaching the most marginalised girls is likely to require a higher unit cost on average. These girls may, for example, need bursaries to support the costs of their schooling, alongside other interventions that ensure they receive a good quality education that is gendersensitive. As such, there may be a choice between supporting a smaller number of the most marginalised with such an integrated approach versus using the same resources to reach a larger number of children who are not in financial need, and so who can be reached at lower cost. Consideration of the potential trade-off between equity and efficiency has been more prevalent in the health sector, which has highlighted that cost-effectiveness ratios provide important 
information to policymakers to support their decisions on what interventions to invest in. However, they recognise that the ultimate choice is likely to involve moral judgements about whether or not their intention is to reach the most marginalised where cost-effectiveness ratios are similar (Cookson et al. 2009; Cookson et al. 2017).

Our motivation for this paper is the recognition that it is vital to provide policymakers with cost-effectiveness analyses that take account of both efficiency and equity considerations, especially when programming for the most marginalised. To illustrate how such analysis can be undertaken, we draw on data collected for a programme aimed at supporting the most marginalised girls in government secondary schools in deprived rural areas in Tanzania, as well as other girls and boys within the same schools, by a non-governmental organisation, the Campaign for Female Education (CAMFED). Using these data, we pose the questions:

1. What is the impact of CAMFED programme for the most marginalised and to what extent are there spill-over effects on other girls and boys?

2. What is the cost-effectiveness of CAMFED's programme in reaching the most marginalised girls in secondary school?

3. How does the cost effectiveness of CAMFED's programme compare to the cost effectiveness of other educational interventions in Southern country contexts?

Our paper makes two important contributions to the literature on cost-effectiveness. First, we present a detailed breakdown of costs across different aspects of CAMFED's reforms aimed at improving both access and learning for the most marginalised girls, as well as other girls and boys, in government secondary schools within deprived rural areas of Tanzania. Second, by drawing on a quasi-experimental research design we present a new approach to analysing costeffectiveness in the education sector that explicitly takes account of equity. Through this analysis, we show that it is likely to cost more to achieve the combined effects of keeping the most marginalised girls in secondary school and improve their learning. We further identify spill-over effects, as learning also improves for those who are not explicitly the target of the intervention (namely less marginalised girls as well as boys). Importantly, we also show that CAMFED's reforms are as cost-effective as those in comparable contexts that do not aim to reach those who are most at risk of being left behind. 


\section{Overview of secondary schooling in Tanzania and CAMFED's programme}

According to Demographic and Health Survey data, ${ }^{i}$ by 2015 almost all of the richest quintile of Tanzanian children completed primary school. However, only around $60 \%$ of the poorest girls and boys do so. This wealth gap in turn influences the extent to which children benefit from secondary school. Recognising that poverty is an important constraint, the Government abolished secondary school fees in 2016 and made secondary education, at least in principle, compulsory. Despite this, in 2015, only around $4 \%$ of girls from the poorest quintile in rural areas completed secondary school, compared with $44 \%$ of boys from the richest quintile in urban areas. Thus, almost all of the benefits of secondary school completion are accrued by more affluent households.

In this context of extremely low access to secondary schooling, particularly in rural areas , CAMFED provides a programme aimed at tackling the multiple dimensions of disadvantage faced by adolescent girls from marginalised backgrounds in government secondary schools, with support from the UK Department for International Development (DFID)'s Girls' Education Challenge $\mathrm{i}^{\mathrm{ii}}$ programme. CAMFED targets a range of barriers to girls' secondary education at an age when they are at particular risk of dropping out due to factors such as poverty, early marriage and teenage pregnancy. Part of this is in the form of financial support for those identified as being in most need to enable them to stay in school. It also provides further support to tackling the barriers that marginalised girls face within schools that potentially impede their learning. This support potentially also benefits other girls and boys in these schools, an issue we address in the paper.

The multidimensional programme includes five core components:

- financial support, covering direct and indirect costs of schooling, is provided for secondary school girls who are identified as most in financial need;

- supplementary learning materials for core subjects (study guides) are provided to all children in CAMFED-supported government schools;

- life skills educational resources, are also provided to all children in CAMFEDsupported government schools;

- the life skills programme and learning support is delivered by young women previously supported by CAMFED because of their own disadvantaged circumstances who provide mentoring support as 'Learner Guides' in their local schools; 
- psycho-social and other forms of support through school-community engagement, including training of teacher mentors, parent support groups and local community authorities, is provided in all schools and communities where CAMFED-supported schools are located (CAMFED 2015).

Between 2013 and 2015, CAMFED provided financial support to 25,938 marginalised girls in 201 government secondary schools in Tanzania. In total, CAMFED reached more than 64,869 girls and 78,330 boys within the schools supported with activities other than financial support.

\section{Cost-effectiveness methods}

Cost-effectiveness analysis allows complex programmes to be summarised in terms of a simple ratio of costs to impact, thereby creating a common measure through which different programmes (from different contexts and in various time periods) can be compared and evaluated (Cellini and Kee 2010). The analysis relies on information of the average unit cost of delivering a programme and an estimate of the average impact of that intervention on the desirable outcome. This gives an estimate of 'average unit cost per unit gained on the outcome' or 'incremental cost per unit of incremental effect' known as the cost-effectiveness ratio. In short, the two key elements of cost-effectiveness analysis are the costs of the intervention and its corresponding impact. ${ }^{\text {iii }}$

\subsection{Measuring Programme Costs of CAMFED's programme in Tanzania}

CAMFED provided us with detailed information on programme costs. ${ }^{\text {iv }}$ This included access to financial records for all aspects of the interventions, including on financial support provided to marginalised girls, provision of gender-sensitive learning and educational materials, mentoring support and community involvement. We disaggregated these data according to start-up, fixed and variable costs (based on a proposed breakdown by Dhaliwal et al. 2013). Start-up costs are one-off costs required to set up an intervention. In CAMFED's programme, this included the development of a new life skills curriculum, for example. An example of fixed costs in CAMFED's programme was the costs of running a district education centre, a cost which is fixed regardless of the number of students being supported. Finally, variable costs depend on the number of beneficiaries, for example providing financial support to marginalised girls in CAMFED's programme. Since this is a new intervention, we follow J-PAL's approach ${ }^{v}$ of including all these costs in the calculation of the unit cost used in the cost-effectiveness analysis. 
In addition to differentiating between types of costs, CAMFED's financial data contains information at different levels of aggregation, namely individual, school, district and centrally at the national level. We assigned costs to each of the five core components of the intervention as follows: Costs identified at the national level, such as those incurred while meeting government officials, were assigned equally across the different components of the intervention. Costs at district and school levels, such as the development of district monitoring tools or training school management committees, varied according to location and assigned to each component respectively. Finally, for cost data recorded at the individual or beneficiary level, we assigned costs to the relevant component of the intervention, the most direct cost being the financial support offered to marginalised girls, which covers around $18 \%$ of all CAMFED's beneficiaries. ${ }^{\mathrm{vi}}$

Having established the different costs and assumptions required to assign costs to the components of the intervention, we then estimated the unit cost of the intervention for each of the components. We do so for each of the components of the intervention separately as not all of them were assigned to all girls and boys, and not all components carried the same cost of delivery. For example, reaching girls in remote areas cost more money. Finally, for each of the core components of the intervention, we took into consideration the different number of beneficiaries (this approach was proposed by Evans and Popova 2016). For example, for financial support, we divided the total cost by the number of the most marginalised girls who receive this. By contrast, for the unit cost of providing CAMFED's study skills programme, which is given to all children in targeted classes in a school, we included both boys and girls in the calculation.

In order to generate the unit cost, we adopted the approach proposed by J-PAL. ${ }^{\text {ii }}$ Costs were adjusted for inflation using the average US inflation rate in the base year of 2013, and used the nominal exchange rate to convert from US dollars to GB pound sterling (as all the costs from CAMFED had already been converted to GB sterling from Tanzanian shillings). The costs were brought into present value using a social discount rate of $10 \%$ per year (similar to the rate used by J-PAL in their estimates). We also adjusted for purchasing power exchange rate for the year of analysis (2016) to adjust for the differences in relative prices between countries (to make our estimates comparable to those of Dhaliwal et al. 2013). Given the unavailability of data, our estimates do not include opportunity costs, for example of community members' time in attending meetings. This means that the unit cost in our calculations are likely to be lower 
compared with the approach proposed by Dhaliwal et al. (2013). However, estimating opportunity costs for such purposes is notoriously difficult.

Based on this approach, Table 1 provides an estimate of the average annual unit cost (in US dollars at current values) for the two years of CAMFED's programme for which we have information on the impact of the programme (2013/14 and 2014/15 academic years). ${ }^{\text {viii }}$ Over the course of these two years, CAMFED spent around $\$ 99.36$ in direct financial support per girl, per year on average (Column A). Indirect unit costs associated with costs of providing financial support, including targeting costs and other activities related to delivering financial support, amounted to $\$ 15.65$, per year on average. The unit cost for other components of the intervention tend to be lower than the direct financial support as these activities are spread over a much larger population of beneficiaries, including all girls and boys attending government secondary schools supported by CAMFED. As shown in Table 1, we therefore estimate $\$ 130.41$ as the overall unit cost to support girls financially, and $\$ 15.40$ to support other girls and boys attending CAMFED-supported schools. Both of these costs are central to the estimation of CAMFED's cost-effectiveness and cannot be separated as the programme aims to support the most marginalised within a multidimensional approach.

$==$ Table 1 about here==

\subsection{Measuring Programme Impact}

As a requirement of DFID's Girls' Education Challenge, CAMFED designed an impact evaluation which took place between 2013 and 2015 using a quasi-experimental approach. For this, 81 government schools that were going to receive support from CAMFED in 2013 were randomly selected from six districts within four regions (Iringa, Morogoro, Pwani and Tanga). In addition, 60 comparison schools in which no intervention took place were randomly selected from four districts within two regions: Dodoma, which neighbours regions in which CAMFED supports schools, and Pwani, in which CAMFED was working in other districts. ${ }^{\text {ix }}$

Once the schools were selected, the whole class within a targeted grade was selected for evaluation purposes and tracked over time. When more than one class was available, one was selected randomly. The selection of the class was based on power calculations to obtain effect sizes over 0.2 standard deviations and taking into account intra-class correlations, in other words, homogeneity of test scores within schools. The evaluation dataset contains information 
on 4,116 girls and 3,632 boys. Of these girls, 1,555 received financial support and a further 1,003 were enrolled in CAMFED-supported schools at baseline. The other 1,588 girls were enrolled in the control schools at baseline. For boys, 2,325 were enrolled in CAMFEDsupported schools at baseline, and the other 1,307 were enrolled in control schools.

Selection of girls with the greatest financial need only took place in intervention districts. The girls were chosen using participatory community-based approaches. For girls attending control schools, it is not possible to know who would have been identified with the greatest financial need following the same participatory approach. However, CAMFED collected information on several demographic and socioeconomic indicators related to government definitions of marginality as laid out in the National Guidelines for the Care and Support of Most Vulnerable Children in Tanzania (CAMFED 2015, 2016) for all girls in treatment and control schools. Using this information, we found that $35 \%$ of girls selected to receive financial support had lost one of their parents, compared with $19 \%$ for the rest of the girls attending CAMFEDsupported schools and $21 \%$ of girls in control schools (Table 2). In addition, $39 \%$ of girls who received financial support lived in female-headed households, compared with $27 \%$ of the rest of girls attending CAMFED-supported schools and $25 \%$ of the girls attending control schools. Across other indicators, girls who received financial support lived in families who were less likely to have secure access to food, poorer in terms of assets, less likely to live in families where the female adult was able to read and write in English, were more likely to have to earn money for the household, and tended to live within families that cannot afford the costs of schooling. Boys attending CAMFED-supported schools were more likely than those in control schools to have lost one of their parents, live in a female headed household, be relatively poorer in terms of assets, but with higher food security relative to boys attending control schools.

\section{$==$ Table 2 about here $==$}

Given differences in socio-economic background characteristics between girls (and boys) attending CAMFED-supported schools and girls (and boys) in control schools, and in particular for girls who received financial support, we employed matching methods to achieve a comparable sample based on their observable characteristics (see Iacus et al. 2011). Our selection of observable factors includes students and household characteristics described in Table 2. These variables were measured at baseline, and therefore assumed exogenous to the intervention and unlikely to be influenced by the intervention. In addition, due to the 
community approach for selecting girls in most need, we include baseline attainment as this is likely to be correlated with some unobservable factors which may make communities more receptive to selecting girls for the intervention (for example girls' attitudes and confidence). In order to find a matched sample, the binary selection model is checked to test the equality of the mean and standard deviation of the observed variables across girls (and boys) in CAMFEDsupported schools and girls (and boys) in control schools. We used the nearest neighbour algorithm with a 1 to 1 match, which means that each girl with financial support is matched with one girl in control schools. Similarly, one girl (boy) who received other support was matched to one girl (boy) from the control school. Although this reduces our sample size, and hence the power in the estimation, the fact that the number of girls in treatment schools stays the same and the control group reduces may not affect power too much (Ho et al. 2007). Additionally, our aim is to generate more comparable groups to improve the precision of our estimates (Stuart 2010).

Figure 1, Panel A, shows the distribution of the propensity score for girls who receive financial support and girls in control group before and after the match. These are the groups with the largest socioeconomic background differences. Before the match, the distribution of the propensity score is skewed to the right, as girls in CAMFED schools were more likely to be selected for financial support according to the observed characteristics compared with girls in control schools. After the 1 to 1 match, the systematic differences highlighted above were captured, and thus we obtained a more comparable group for the analysis. The distribution of the propensity score after the match is almost identical for girls receiving financial support and comparable girls in control schools. This result was also obtained for the matched sample between girls (boys) attending CAMFED-supported schools and girls (boys) attending control schools (see Panel B and Panel C, respectively, in Figure 1).

Baseline equivalences on the observable student and household factors using matched samples are demonstrated in Appendix 1. Given the quality of the data, the use of matching methods has enabled an identification strategy for the estimation of causal effects which is based on a range of observable factors. However, as it is the case with matching methods, we are unable to account for selection bias based on unobservable factors. Thus, the use of the matched sample enables a more accurate estimate of the differences in dropout rates and test scores, although estimates remain subject to selection bias based on unobservables.

$==$ Figure 1 about here== 
We include two outcomes of interest: reductions in dropout and improvements in learning (see Table 2). School dropout was measured by the change in the dropout rate during the two academic years between girls (and boys) attending CAMFED-supported schools relative to those attending control schools. Learning gains were measured using test scores in mathematics and English, on a 0-100 scale. ${ }^{\mathrm{x}}$ We normalised learning score (mean 0 and standard deviation 1) based on girls who were part of the baseline and midline. At this stage, we did not take account of the dropout rates estimated above. It is possible, however, that the CAMFED intervention could change the composition of those who remain in school. For example, the CAMFED intervention could enhance retention of girls who received financial support who, as shown above, were more likely to come from poorer and more disadvantaged households.

The changing composition of the cohort due to dropout, and the association between dropout and poverty, is likely to affect the estimation of test scores two years after the intervention. Unfortunately, two years after the intervention started, CAMFED only collected information for those girls and boys who remained in school. For this reason, any estimated effect of the programme on learning outcomes is likely to be underestimating the true effect of the intervention as CAMFED is enabling poorer and potentially lower performing girls and boys to remain in education, whereas comparable girls and boys would have dropout from control schools in the absence of support. However, we expect the cohort composition effect to be relatively small in our dataset. This is due to the low dropout rate difference between treatment and control, less than $3 \%$, as shown in Table 2.

Groenwold et al. (2014) suggest the use of multiple imputation on the missing information from the outcome variable, in our case test scores, as a plausible method to deal with the cohort composition. Following this, we use information from baseline test scores and relevant demographic and socioeconomic factors which predict attainment, such as poverty and household composition, to estimate imputed values for the test scores two years after the intervention for those for whom we do not have this information. Since we input five datasets with plausible values of the test scores for girls and boys who dropped out of the programme, we adjust the estimation of programme effects for the fact that we apply multiple imputation methods (Groenwold et al. 2014; Mitra and Reiter 2016; Sterne et al. 2009; Rubin 1996). We use multiple imputation methods after the 1 to 1 matching procedure was established and the comparable sample for estimation obtained. 


\subsection{Measuring Programme Cost-effectiveness}

We adopt two formulae to calculate the cost-effectiveness of CAMFED's programme. The first is comparable to the approach used in other analysis but with consideration of equity by differentiating between the populations being supported. The second formula takes the analysis according to equity further.

Formula (1): Weighted cost effectiveness ratio

$$
C E R=\frac{T C_{F S}}{\text { impact }_{F S} \times N_{F S}}\left(\frac{N_{F S}}{N}\right)+\frac{T C_{N F S}}{\text { impact }_{N F S} \times N_{N F S}}\left(\frac{N_{N F S}}{N}\right)
$$

Formula 1 includes the total cost (TC),

○ to the most marginalised girls who receive financial support (FS), identified as $T C_{F S}$. This contains the cost of the bursary itself and its administrative costs, as well as the cost of providing learning and educational materials, mentoring and community support;

and

$\circ$ to less marginalised girls and boys (NFS): $T C_{N F S}$. These are young people who do not receive financial support but do receive other aspects of the intervention by being in CAMFED-supported schools.

Impact is measured by the standard deviation increase in learning outcomes using the relative difference in test scores between young people in CAMFED-supported schools and those in control group schools before and after the intervention. Recognising heterogeneity in impact from the intervention for different population groups, this impact is measured separately for girls in CAMFED-supported schools who receive financial support, and for girls and boys in CAMFED-supported schools who do not receive financial support. This analysis was possible because CAMFED generated identification numbers in its dataset that enabled us to link financial records with background information, school enrolment status and learning outcomes for the sub-sample of beneficiaries for whom data was collected for evaluation purposes.

The cost-effectiveness ratio for the CAMFED intervention is then weighted according to the number $(\mathrm{N})$ in each of the groups supported: 
- $\mathrm{N}_{\mathrm{FS}}$ is the total number of girls who received financial support

- $\mathrm{N}_{\mathrm{NFS}}$ is total number of girls and boys in all CAMFED schools excluding those who received financial support.

Unlike other estimates in the empirical literature, Formula (1) takes account of equity with respect to the fact that the core of CAMFED's support is to provide additional resources to those in most financial need who would not otherwise attend school. In addition, Formula (1) could be extended to further differentiate between different sub-groups of beneficiaries. For instance, the second term of the weighted cost effectiveness could be further separated according to gender, poverty, disability or any other marker of disadvantage. For the case of CAMFED, where both boys and girls are beneficiaries who attend CAMFED-supported schools, the extended formula can be described by:

Formula (1.1): Weighted cost effectiveness ratio (different groups)

$$
\begin{gathered}
C E R=\frac{T C_{F S}}{\text { impact }_{F S} \times N_{F S}}\left(\frac{N_{F S}}{N}\right)+\frac{T C_{\text {Gilrs_NFS }}}{\text { impact }_{\text {Gilrs_NFS }} \times N_{\text {Girls_NFS }}}\left(\frac{N_{\text {Girls_NFS }}}{N}\right) \\
+\frac{T C_{\text {Boys_NFS }}}{\text { impact }_{\text {Boys_NFS }} \times N_{\text {Boys_NFS }}}\left(\frac{N_{\text {Boys_NFS }}}{N}\right)
\end{gathered}
$$

By contrast to most cost-effectiveness ratios in the empirical literature, Formula 1.1 does not assume homogeneity of the population of supported beneficiaries and hence divides between the population of beneficiaries with different types of support and different characteristics.

However, undertaking a separate cost effectiveness analysis for sub-groups of beneficiaries does not address other equity concerns. Notably it only contains estimates of the learning gains due to CAMFED's support targeted at improving learning, and thus ignores the fact that a significant proportion of girls in CAMFED-supported schools may now be able to learn because they have been able to stay in school thanks to the financial support provided.

In order to address this important issue, we use Johri and Norheim's (2012) methodology which integrates equity concerns into their cost-effectiveness analysis of health interventions. Specifically, we include an equity weight in the cost-effectiveness ratio that takes account of improvements in retention for each of the populations of beneficiaries: those who receive financial support; and all those who attend CAMFED-supported schools (including all children not receiving financial support). It is possible that retention is improved for both groups, but the key equity element that is taken into account in this analysis is that CAMFED is prepared to spend more on girls in financial need. 
Formula (2): Weighted cost effectiveness ratio, taking account of retention:

$$
C E R=\frac{T C_{F S}}{\text { impact }_{F S} \times\left[O R_{F S} \times N_{F S}\right]}\left(\frac{N_{F S}}{N}\right)+\frac{T C_{N F S}}{\text { impact }_{N F S} \times\left[O R_{N F S} \times N_{N F S}\right]}\left(\frac{N_{N F S}}{N}\right)
$$

Building on Formula (1), Formula (2) is weighted using an estimate of the odds ratio of the reduction in drop out/increase in retention,

- for girls supported financially by CAMFED relative to comparable girls in the control group: $O R_{F S}$

and

- for girls and boys who are not supported financially relative to equivalent girls and boys in the control group: $O R_{N F S}$

The difference between Formula (2) and (1) provides an estimate of the effectiveness gains for improving retention. Formula (2) can be further extended to include reduction in dropout for specific sub-groups of beneficiaries. The main challenge with the extension of the framework is the ability of the evaluation design to detect significant statistical effects for sub-groups of the targeted populations. This, in general, requires large sample sizes for both treatment and control groups, which are likely to be more costly to implement. For the case of CAMFED, we provide an extended analysis of cost-effectiveness with equity to include girls supported financially, and then separately girls and boys attending CAMFED-supported schools as described in the following extended formula:

Formula (2.1): Weighted cost effectiveness ratio, taking account of retention (different groups)

$$
\begin{aligned}
C E R=\frac{T C_{F S}}{\text { impact }_{F S} \times\left[O R_{F S} \times N_{F S}\right]}\left(\frac{N_{F S}}{N}\right) \\
+\frac{T C_{\text {Girls_NFS }}}{\text { impact }_{\text {Girls_NFS }} \times\left[O R_{\text {Girls_NFS }} \times N_{\text {Girls_NFS }}\right]}\left(\frac{N_{\text {Girls_NFS }}}{N C_{\text {Boys_NFS }}}\right) \\
\left.+\frac{N_{\text {Boys_NFS }}}{N}\right)
\end{aligned}
$$

\section{Impact of CAMFED's programme}

In order to estimate the impact of the programme on learning outcomes, we used the 1-to-1 matched sample with the inclusion of multiple imputations to deal with cohort compositional 
changes due to dropout, as discussed in Section 3.2. As shown in Table 2, there are no initial differences in Maths or English test scores between girls (and boys) in CAMFED-supported schools and those in control schools, which partially supports the parallel trend assumption required to estimate changes in learning outcomes over time using difference-in-differences. ${ }^{\mathrm{xi}}$ Table 3 shows the estimated difference in test scores between girls (and boys) in CAMFEDsupported schools and those in control schools, controlling for multiple imputation datasets, area fixed effects and clustering standard errors for school effects. Results show that girls who received financial support increased their test scores by 1.10 standard deviations in Maths and 0.58 standard deviations in English relative to comparable girls in control schools. Estimates of similar magnitude in test score improvements are shown for other girls who attended CAMFED-supported schools relative to comparable girls in control schools. Finally, boys who attended CAMFED-supported schools improved their Maths test scores by 0.66 standard deviations and their English test scores by 0.44 standard deviations relative to comparable boys in control schools.

Compared to similar education interventions in Southern countries, the impact of CAMFED's intervention is high (for example, compared with studies by Duflo et al. 2011; Kremer et al. 2009, 2013). J-PAL (2014) proposes that interventions with effect sizes of more than 0.5 standard deviation are considered as having very large impact. Therefore, the estimated impact of the CAMFED programme for girls who receive financial support (as well as those who do not) relative to comparable girls in control schools would be considered very large. The estimated impact for boys in CAMFED schools relative to comparable boys in control schools would be considered large. This suggests that CAMFED's interventions targeting the most marginalised girls is also having spill-over effects on other girls as well as boys.

For our estimations of the cost effectiveness of CAMFED's programme, we only use results from English test scores. Since the improvement in English as measured by tests scores is lower than maths, the results are likely to be a conservative estimate of the cost-effectiveness of the programme. A reason for the much larger impact in maths is because the control group showed only a very small, if any, improvement in learning. ${ }^{\text {xii }}$

$==$ Table 3 about here $==$

As learning gains would only be expected for the sub-group of girls and boys who remained in school during the period of the intervention, improving retention was another important aim of 
the CAMFED programme, in particular for girls who received financial support. Results from Table 3 show that the programme reduced the likelihood of drop out for girls who received financial support. The estimated odds of drop out are 0.75 for the most marginalised girls supported financially relative to similar girls in the control group, suggesting that the most marginalised girls receiving CAMFED's support are less likely to dropout. The estimated odds of drop out for other girls and boys were not statistically significant different from 1 (in this case no impact) relative to comparable girls and boys in control schools.

\section{Cost Effectiveness and Equity in Cost Effectiveness}

This section responds to the first research question, namely identifying the cost-effectiveness of CAMFED's programme. The cost effectiveness ratio for each of the population groups analysed is shown in Table 4 . We use $18 \%$ of the beneficiaries girls who received direct financial support, $27 \%$ and $55 \%$ of girls and boys who benefited from the wider programme, respectively, as relative weights in the estimation of the cost-effectiveness ratio using the formulae above. For comparability with interventions in other studies (see Section 6), we focus here on the cost-effectiveness ratio presented as a standard deviation increase for every $\$ 100$ (column 2 in Table 4). ${ }^{\text {xii }}$ For every $\$ 100$ spent, the standard deviation increase in English scores is 0.23 for girls receiving financial support (i.e. those in most need), 1.96 for other girls in CAMFED-supported schools, and 1.42 for boys in CAMFED-supported schools. Using Formula (1.1) this results in an estimated weighted average of 0.75 for all students in the programme.

The reason for the apparent lower cost-effectiveness for financially supported girls is because of the inevitable higher cost of reaching these girls, not because of lower gains in their English scores compared with other girls and boys in those schools. As has been shown, the impact of this spending on their retention in school and learning has been significant. As the later part of this paper makes clear, such financial support is vital to enable these girls to stay in school, and so benefit from the reforms that all children in the school are receiving. Without the financial support, the cost-effectiveness ratio might appear higher, but this would only reach a sub-set of girls and boys who are already able to be in school, and so not amongst the most disadvantaged.

The final column converts this standard deviation into an equivalent estimate in terms of additional years of schooling per $\$ 100$ spent. For this, we adopt the approach proposed by 
Romero et al. (2017) who use an increase in learning from one year of the control group as the basis for converting their results of the evaluation of the partnership Schools for Liberia into additional years of schooling. ${ }^{\text {xiv }}$ For CAMFED's programme in Tanzania, English test scores increased by 0.52 of a standard deviation for the control group. Using Romero et al.'s approach, this therefore means we assume that, in general, it is expected that spending one year in school is equivalent to 0.52 standard deviations. From this, we can estimate the overall costeffectiveness of girls receiving financial support. Given their English test scores improved by an additional 0.23 standard deviations per $\$ 100$ compared to the control group, this is equivalent to an additional 0.4 of a year in school (an addition of 0.23 standard deviations divided by 0.52 standard deviations for the control group equals 0.43 additional years in school). For other girls and boys who received other support, the equivalent increase per $\$ 100$ is 3.76 and 2.72 additional years in school, respectively (see Table 4). In summary, for all students, for every \$100 spent, CAMFED's programme improved English learning outcomes equivalent to spending an additional 1.45 years in school.

$==$ Table 4 about here==

Table 5 shows our estimation of cost-effectiveness including equity considerations due to increased retention proposed in Formula (2.1). Results show that, taking into account reductions in dropout, the overall cost-effectiveness of CAMFED's programme increases to 1.09 standard deviations per $\$ 100$ (compared to 0.75 estimated previously). Translating this into years of schooling, we estimate that the effectiveness of CAMFED's programme that takes account both improvements in both access and learning is equivalent to an additional two years of schooling for all girls and boys per $\$ 100$ (compared with 1.45 years in the previous calculations).

$==$ Table 5 about here $==$

\section{Comparing the cost effectiveness of CAMFED's progrmame with other related educational interventions}

In the final section of this paper, we respond to the third question: How does the cost effectiveness of CAMFED's programme compare to the cost effectiveness of other educational 
interventions in Southern country contexts? In order to answer this, we plot our estimates of the cost effectiveness of CAMFED's programme transformed into additional standard deviation gains per $\$ 100$ cost incurred (see Figure 2). We use cost-effectiveness with equity obtained from Formula 2.1. We also include in Figure 2 the 90 percent confidence intervals of the cost effectiveness ratio based on the standard errors of the impact estimates.

CAMFED's intervention appears to position well within the range of cost-effectiveness of educational interventions within sub-Saharan Africa (see Figure 2). On average, the estimate for CAMFED's multidimensional programme is similar to the girls' merit scholarship intervention in Kenya, and considerably higher than the cost-effectiveness of the Malawi conditional cash transfer programme and the Partnership Schools for Liberia programme. Averages are higher for the Kenya contract teaching and streaming programme and intervention providing textbooks for the top quintile. However, the confidence intervals for the Kenyan programmes are wide. The overlap of confidence intervals with CAMFED's estimates suggests that there may not be a significant difference in the cost-effectiveness across these programmes compared with CAMFED's.

It is also worth noting that comparisons such as these are not necessarily meaningful as interventions vary so vastly in terms of type, target population, context, education level, among other factors. From the interventions mentioned in Figure 2, very few are closely related to CAMFED's approach. In particular, there are differences in two key focus areas, namely the level of education (CAMFED focuses on secondary education which tends to have higher unit costs compared with primary schooling) and the target population (CAMFED targets the most marginalised from very remote and disadvantaged communities).

$==$ Figure 2 about here $==$

To give one comparison, Kremer et al. (2009) estimate a gain of 1.38 standard deviation per $\$ 100$ cost for Kenya’s Girls' Scholarship Programme (Kremer et al. 2009). This appears higher than the 1.09 standard deviation gain per \$100 for CAMFED's intervention in English, but lower than the gain for maths. However, the scholarship programme in Kenya is not directly comparable as it differs in important ways in terms of the target population: the programme provided scholarships to 6 th grade girls scoring within the top $15 \%$ in government administered tests. As such, while the scholarship programme in Kenya was aimed at high achieving girls 
and provided scholarship based on academic merit, the CAMFED programme was aimed at girls in remote rural areas and targeted financial support to those in most need regardless of academic merit. In addition, although the point estimate for the Kenya programme is higher than for CAMFED's gain in English, the confidence intervals are large, potentially showing no statistical difference with respect to the CAMFED programme. In addition, CAMFED's gain in maths is higher. ${ }^{\mathrm{xv}}$ The cost-effectiveness of CAMFED's multidimensional programme which reaches the most marginalised could therefore be similar to the scholarship programme evaluated in Kenya to reach the top performing girls academically. To the extent that policy actors make decisions based on evidence of cost-effectiveness, they would need to make moral judgements on whether they choose to reach the most marginalised or the best performing students in choosing between such programmes.

Another comparison could be made with the intervention providing contract teachers together with the streaming of children in classes in Kenya. This intervention also included a component that aimed to reduce class size by hiring local teachers (Duflo et al. 2011). The estimated cost effectiveness of the intervention in Kenya was a 1.97 standard deviation increase in test scores per $\$ 100$ cost, compared with 1.09 for CAMFED's programme for English. Again, there is a need to be careful with a direct comparison of the cost effectiveness of these programmes. Notably, while the cost-effectiveness of the Kenyan intervention appears higher, the estimated impact is far higher for CAMFED's programme, which increased the combined weighted learning by 0.71 standard deviations, compared to only 0.23 standard deviations in the Kenyan programme. Given the more limited scope of the Kenyan programme, including that it was not targeted on the most marginalised, its cost was relatively low (an average cost per student of \$11 compared with \$133 for financially-supported girls who needed these resources to stay in school, and $\$ 15.40$ for other girls and boys for CAMFED). In this case, policy actors would potentially need to make judgements on whether they would prefer to choose to achieve high impact on learning for the most marginalised at a greater cost (as in CAMFED's programme(, or lower impact at lower cost for a wider population (as in the Kenya example).

\section{Discussion}

To recap, we use the case of CAMFED in Tanzania to show that it is both possible and desirable to take equity more explicitly into account in cost-effectiveness analysis. Reaching the most marginalised is likely to require higher costs for programmes as they require multidimensional approaches both to enable to them to stay in school (for example with bursaries to cover the 
costs of their schooling) as well as to improve the quality of their education. The CAMFED programme is an example of such a multidimensional programme. These programmes may also have spill-over effects on beneficiaries more widely beyond those specifically being targeted (in this case including boys who attend the CAMFED-supported schools), and so this should also be taken into account in assessing their cost-effectiveness.

Our analysis of CAMFED's programme shows that, while it may be more costly to reach the most marginalised, the impact is impressive. In taking into account both access and learning, we find that CAMFED's programme results in improved learning of an equivalent of around 2 years in secondary school for every $\$ 100$ spent for the most marginalised girls. The analysis also confirms positive spill-over effects on other girls and boys in CAMFED-supported government secondary schools in deprived rural areas of Tanzania. The findings, therefore, suggest that a programme aimed at targeting the most marginalised can have wider benefits. While the additional costs of bursaries is important to reduce the most marginalised's likelihood of dropping out, the benefits of the programme more generally should be seen across all of those in those within their classrooms. Including these spill-over effects means that the programme is likely to be even more cost-effective.

It is difficult to make meaningful comparisons with the cost-effectiveness interventions of other programmes given their different contexts and target groups (many of them do not aim to reach the most marginalised), different nature of the interventions (many are individual interventions, rather than CAMFED's multidimensional approach), and different parts of the education system that are addressed (many are at the primary level, for which interventions may be less expensive). Even so, comparisons show that CAMFED's multidimensional programme has been able to attain similar cost-effectiveness outcomes to ones that have not included the aim of reaching the most marginalised.

Taking into account complexities in cost-effectiveness analysis is not straightforward. As not all population groups benefit equally from the support provided by different interventions, and the costs of reaching these groups is likely to vary, this should be considered whenever possible in cost-effectiveness analysis. Additionally, it is important to consider intermediary outcomes (such as on reducing dropout from school in the CAMFED example) which are necessary for improving learning of the most marginalised. With this in mind, we attempt to take account of equity in the analysis by paying attention to the differential support offered to the most marginalised girls, the differential impact of the intervention for girls and boys, and the 
improvements in access for the most marginalised along with improvements in learning for all those supported.

In taking this work forward, our analysis could be extended further to assess other potential spill-over effects of interventions, such as potential benefits for siblings of beneficiaries and other children in the community who could have benefited as a result of the intervention. Further research would also benefit from including consideration of cost-effectiveness analysis using the impact on a broader set of skills beyond English and maths, such as ones related to socio-emotional skills. 


\section{References}

CAMFED International, 2015. A New Equilibrium for Girls - Tanzania and Zimbabwe Baseline. Project Reference Number 5101. Girls’ Education Challenge, UK AID. Accessible at https://CAMFEDorg2015.s3.amazonaws.com/uploads/files/CAMFED_5101_SCW_B aseline.pdf

CAMFED International, 2016. A New "Equilibrium” for Girls - Tanzania and Zimbabwe Midline Evaluation Report. Project Reference: 5101. Girls’ Education Challenge, UK AID. Accessible at https://CAMFEDorg2015.s3.amazonaws.com/uploads/files/CAMFED_5101_SCW Midline.pdf.

Cellini, S., and J. Kee. 2010. "Cost-Effectiveness and Benefit-Cost Analysis.” In Handbook of Practical Program Evaluation, edited by W. Joseph, H. Harry, and K. Newcomer, 493-530. San Francisco, CA: John Wiley.

Cookson, R., M. Drummond, and H. Weatherly. 2009. "Explicit incorporation of equity considerations into economic evaluation of public health interventions." Health Economic Policy Law 4 (Pt 2): 231-45. doi: 10.1017/S1744133109004903

Cookson, R., et al. 2017. "Using cost-effectiveness analysis to address health equity concerns." Value in Health 20: 206-212. https://doi.org/10.1016/j.jval.2016.11.027

Delprato, M., B. Alcott, P. Rose, and R. Sabates. 2017. Analysing cost-effectiveness of raising learning for marginalised girls through Camfed's programme: A methodological note. REAL Centre, University of Cambridge. Accessible at http://www.educ.cam.ac.uk/centres/real/downloads/Policy\%20papers/REAL\%20Polic y\%20Brief\%20Camfed\%20A4_FINAL.pdf

Department for International Development, 2011. DFID's Approach to Value for Money (VfM), Accessible at: https://www.gov.uk/government/uploads/system/uploads/attachment_data/file/49551/ DFID-approach-value-money.pdf

Dhaliwal, I., and C. Tulloch. 2012. "From research to policy: Using evidence from impact evaluations to inform development policy." Journal of Development Effectiveness 4 (4): 515-536. https://doi.org/10.1080/19439342.2012.716857

Dhaliwal, I., E. Duflo, and R. Glennerster. 2013. "Comparative cost effectiveness analysis to inform policy in developing countries: a general framework with applications for 
education." In Education Policy in Developing Countries, edited by P. Glewwe, 285338. Chicago: University of Chicago Press.

Duflo, E., P. Dupas, and M. Kremer. 2011. "Peer Effects, Teacher Incentives, and the Impact of Tracking: Evidence from a Randomized Evaluation in Kenya." American Economic Review 101 (August): 1739-1774. doi: 10.1257/aer.101.5.1739

Evans, D. K., and A. Popova. 2016. "Cost-Effectiveness Analysis in Development: Accounting for Local Costs and Noisy Impacts.” World Development 77(C): 262-276. https://doi.org/10.1016/j.worlddev.2015.08.020

Groenwold, R. H., K. G. M Moons, and J. P. Vandenbroucke. 2014. "Randomized trials with missing outcome data: how to analyze and what to report." Canadian Medical Association Journal 186 (15): 1153-1157. doi: 10.1503/cmaj.131353

Ho, D.E.,K. Imai, G. King, and E. A. Stuart. 2007. "Matching as nonparametric preprocessing for reducing model dependence in parametric causal inference." Political Analysis 15(3): 199-236. doi:10.1093/pan/mp1013

Iacus, S. M., G. King, and G. Porro. 2011. "Multivariate Matching Methods that are Monotonic Imbalance Bounding." Journal of the American Statistical Association 106: 345-361. doi:10.1198/jasa.2011.tm0959

Johri, M., and O.F. Norheim. 2012. "Can cost-effectiveness analysis integrate concerns for equity? Systematic review.” International Journal of Technology Assessment in Health Care 28(2): 125-32. doi: 10.1017/S0266462312000050.

Kiessel, J., and A. Duflo. 2014. Cost-effectiveness report: The teacher community assistant initiative (TCAI). Retrieved 15/01/2018, from https://www.povertyaction.org/publication/teacher-community-assistant-initiative-cost-effectivenessreport

Kremer, M., and A. Holla. 2009. "Improving Education in the Developing World: What Have We Learned from Randomized Evaluations?" Annual Review of Economics 1: 513542. http://dx.doi.org/10.1146/annurev.economics.050708.143323

Kremer, M., E. Miguel, and R. Thornton. 2009. "Incentives to learn." The Review of Economics and Statistics 91: 437-456. https://doi.org/10.1162/rest.91.3.437

Kremer, M., C. Brannen, and R. Glennerster. 2013. "The Challenge of Education and Learning in the Developing World.” Science 340: 297-299.

Levin, H., and C. Belfield. 2015. "Guiding the Development and Use of Cost-Effectiveness Analysis in Education." Journal of Research on Educational Effectiveness 8(3): 400418. https://doi.org/10.1080/19345747.2014.915604 
Masset, E., G. Mascagni, A. Acharya, E. M. Egger, and A. Saha. 2018. "Systematic reviews of cost-effectiveness in low and middle income countries: a review of reviews." Journal of Development Effectiveness 10(1): 95-120. DOI: $10.1080 / 19439342.2018 .1439079$

McEwan, P. J. 2012. "Cost-effectiveness analysis of education and health interventions in developing countries." Journal of Development Effectiveness 4: 189-213. https://doi.org/10.1080/19439342.2011.649044

McEwan, P. J. 2015. "Improving learning in primary schools of developing countries: A meta-analysis of randomized experiments." Review of Educational Research 85: 353 394. https://doi.org/10.3102/0034654314553127

Mitra, R., and J.P. Reiter. 2016. “A comparison of two methods of estimating propensity scores after multiple imputation." Statistical Methods in Medical Research 25(1): 188-204. doi: 10.1177/0962280212445945

Romero, M., J. Sandefur, and W. A. Sandholtz. 2017. “Can Outsourcing Improve Liberia's Schools? Preliminary Results from Year One of a Three-Year Randomized Evaluation of Partnership Schools for Liberia." Centre for Global Development Working Paper 462. Washington, DC: Center for Global Development. Accessible at: https://www.cgdev.org/publication/partnership-schools-for-liberia.

Rubin, D. B. 1996. "Multiple imputation after 18+ years.” Journal of the American Statistical Association 91: 473-489.

Snilstveit, B., et al. 2016. "The impact of education programmes on learning and school participation in low- and middle-income countries: a systematic review summary report.” 3ie Systematic Review Summary 7. London: International Initiative for Impact Evaluation (3ie). Accessible at: https://www.3ieimpact.org/evidencehub/publications/systematic-review-summaries/impact-education-programmeslearning-school-participation-low-and-middle-income-countries

Sterne, J. A., et al. 2009. "Multiple imputation for missing data in epidemiological and clinical research: potential and pitfalls." British Medical Journal 338: b2393. doi: https://doi.org/10.1136/bmj.b2393

Stuart, E. A. 2010. "Matching methods for causal inference: A review and a look forward." Statistical Science 25(1): 1-21. doi:10.1214/09-STS313

Uneze, E., and I. Tajudeen. 2013. "Understanding cost-effectiveness and benefit-cost analysis using data on school feeding and education assistance programmes in Nigeria." 
Journal of Development Effectiveness 5(3): 381-399. doi:

$10.1080 / 19439342.2013 .787111$ 
Appendix 1: Background characteristics by treatment and gender for matched samples

\begin{tabular}{|c|c|c|c|c|c|c|c|c|c|c|}
\hline & \multirow{2}{*}{\multicolumn{3}{|c|}{$\frac{\text { Girls financial and other support }}{\text { Matched samples }}$}} & \multirow{2}{*}{\multicolumn{3}{|c|}{$\begin{array}{l}\text { Girls other support } \\
\text { Matched samples }\end{array}$}} & \multirow{2}{*}{\multicolumn{4}{|c|}{$\begin{array}{c}\text { Boys other support } \\
\text { Matched samples }\end{array}$}} \\
\hline & & & & & & & & & & \\
\hline & \multirow{2}{*}{$\begin{array}{l}\text { Treatment } \\
\text { Mean }\end{array}$} & \multirow{2}{*}{$\begin{array}{l}\text { Control } \\
\text { Mean }\end{array}$} & Difference & \multicolumn{2}{|c|}{ Treatment Control } & \multirow[t]{2}{*}{ Difference } & \multirow{2}{*}{\begin{tabular}{|l|} 
Treatment \\
Mean
\end{tabular}} & \multirow{2}{*}{$\begin{array}{l}\text { Control } \\
\text { Mean }\end{array}$} & \multicolumn{2}{|c|}{ Difference } \\
\hline & & & & Mean & Mean & & & & & \\
\hline \multicolumn{11}{|l|}{ Panel A: Outcomes } \\
\hline \multicolumn{11}{|l|}{ Maths } \\
\hline Score at baseline & -0.091 & -0.090 & -0.001 & -0.021 & 0.001 & -0.022 & -0.083 & -0.058 & -0.026 & \\
\hline \multicolumn{11}{|l|}{ English } \\
\hline Score at baseline & -0.123 & -0.069 & -0.054 & -0.002 & -0.013 & 0.011 & -0.116 & -0.057 & -0.058 & \\
\hline \multicolumn{11}{|l|}{ Panel B: Students, household characteristics } \\
\hline Age & 15.901 & 15.937 & -0.036 & 15.796 & 15.778 & 0.018 & 16.577 & 16.454 & 0.123 & $*$ \\
\hline Form 3 & 0.789 & 0.800 & -0.010 & 0.769 & 0.764 & 0.005 & 0.763 & 0.780 & -0.017 & \\
\hline Number of adults in the household & 3.027 & 3.045 & -0.017 & 3.140 & 3.185 & -0.046 & 3.394 & 3.314 & 0.080 & \\
\hline Number of children under age 6 & 1.061 & 1.046 & 0.015 & 0.933 & 0.973 & -0.040 & 1.080 & 1.036 & 0.044 & \\
\hline Lost a father or mother ( $1=y e s)$ & 0.248 & 0.253 & -0.005 & 0.187 & 0.190 & -0.003 & 0.194 & 0.220 & -0.026 & \\
\hline Household head ( $1=$ female $)$ & 0.301 & 0.323 & -0.022 & 0.255 & 0.254 & 0.000 & 0.222 & 0.236 & -0.013 & \\
\hline Female head/spouse can read/write in English (1=yes) & 0.154 & 0.159 & -0.005 & 0.196 & 0.228 & -0.032 & 0.157 & 0.168 & -0.012 & \\
\hline Child earns money for the household ( $1=y e s$ ) & 0.356 & 0.367 & -0.011 & 0.320 & 0.324 & -0.004 & 0.536 & 0.529 & 0.007 & \\
\hline Food security ( $1=$ always have enough food $)$ & 0.391 & 0.398 & -0.007 & 0.522 & 0.526 & -0.004 & 0.359 & 0.373 & -0.013 & \\
\hline Distance to school (more than 2 hours) & 0.192 & 0.179 & 0.013 & 0.207 & 0.192 & 0.014 & 0.199 & 0.194 & 0.006 & \\
\hline Cost of schooling ( $1=$ Parents cannot afford $)$ & 0.468 & 0.494 & -0.027 & 0.398 & 0.381 & 0.016 & 0.402 & 0.410 & -0.008 & \\
\hline Asset index (based on ownership of 7 assets) & -0.033 & -0.056 & 0.023 & 0.136 & 0.157 & -0.021 & 0.123 & 0.076 & 0.047 & \\
\hline \# districts & 6 & \multicolumn{2}{|c|}{4} & 6 & \multicolumn{2}{|c|}{4} & 6 & \multicolumn{3}{|l|}{4} \\
\hline \# schools & 81 & \multirow{2}{*}{\multicolumn{2}{|c|}{60}} & 81 & \multirow{2}{*}{\multicolumn{2}{|c|}{60}} & 81 & \multirow{2}{*}{\multicolumn{2}{|c|}{60}} & \\
\hline N (Matched Sample) & 2,018 & & & 1,704 & & & 2,376 & & & \\
\hline
\end{tabular}

Notes: Asterisks *, ** indicated statistical differences between samples at $5 \& 1 \%$ level, respectively. All analyses are based on the matched subsamples. 
Table 1. Average unit cost (current US\$) per year

\begin{tabular}{|c|c|c|}
\hline Costs & Girls supported financially & $\begin{array}{c}\text { All Other Girls \& } \\
\text { Boys Supported }\end{array}$ \\
\hline & Full unit cost & Full unit cost \\
\hline $\begin{array}{l}\text { 1a Direct financial } \\
\text { support } \\
\text { 1b Indirect financial }\end{array}$ & 99.36 & N/A \\
\hline support & 15.65 & N/A \\
\hline 2 Study Guides & 3.86 & 3.86 \\
\hline 3 Life Skills & 3.78 & 3.78 \\
\hline 4 Learner Guides & 2.38 & 2.38 \\
\hline $\begin{array}{l}5 \text { School Community } \\
\text { engagement } \\
\text { Total unit cost }\end{array}$ & $\begin{array}{c}5.38 \\
\mathbf{1 3 0 . 4 1}\end{array}$ & $\begin{array}{c}5.38 \\
\mathbf{1 5 . 4 0}\end{array}$ \\
\hline
\end{tabular}


Table 2. Outcomes and background characteristics by treatment and gender

\begin{tabular}{|c|c|c|c|c|c|c|c|c|c|c|c|c|}
\hline & \multicolumn{4}{|c|}{ Treament schools } & \multirow{2}{*}{\multicolumn{2}{|c|}{$\begin{array}{l}\text { Control schools } \\
\text { Girls no support }\end{array}$}} & \multirow{2}{*}{\multicolumn{3}{|c|}{\begin{tabular}{|l|} 
Treatment schools \\
Boys other support \\
\end{tabular}}} & \multirow{2}{*}{\multicolumn{2}{|c|}{$\begin{array}{l}\text { Control schools } \\
\text { Boys no support }\end{array}$}} & \\
\hline & \multicolumn{4}{|c|}{$\begin{array}{l}\text { Girls financial support Girls other support } \\
\& \text { other }\end{array}$} & & & & & & & & \\
\hline & $\begin{array}{l}\text { Mean } \\
(1)\end{array}$ & $\begin{array}{l}\mathrm{SD} \\
(2)\end{array}$ & $\begin{array}{l}\text { Mean } \\
(3)\end{array}$ & $\begin{array}{l}\text { SD } \\
(4)\end{array}$ & $\begin{array}{l}\text { Mean } \\
(5)\end{array}$ & $\begin{array}{l}\mathrm{SD} \\
(6)\end{array}$ & & \begin{tabular}{|l|} 
Mean \\
$(7)$
\end{tabular} & $\begin{array}{l}\mathrm{SD} \\
(8)\end{array}$ & $\begin{array}{l}\text { Mean } \\
\text { (9) }\end{array}$ & $\begin{array}{l}\text { SD } \\
(10)\end{array}$ & \\
\hline \multicolumn{12}{|l|}{ Panel A: Outcomes } & Maths \\
\hline Score at baseline & -0.097 & 1.005 & 0.023 & 1.185 & -0.041 & 0.976 & $* *$ & -0.025 & 1.037 & -0.054 & 0.981 & \\
\hline Score at midline & 1.126 & 1.256 & 1.247 & 1.422 & -0.007 & 0.996 & $* *$ & 0.667 & 1.091 & 0.000 & 1.000 & ** \\
\hline \multicolumn{13}{|l|}{ English } \\
\hline Score at baseline & -0.144 & 1.024 & 0.015 & 1.172 & -0.074 & 0.996 & ** & -0.068 & 1.035 & -0.072 & 1.007 & \\
\hline Scores at midline & 0.497 & 0.976 & 0.701 & 1.029 & -0.006 & 0.998 & ** & 0.416 & 0.954 & 0.000 & 0.998 & ** \\
\hline Dropout & 0.097 & 0.296 & 0.141 & 0.348 & 0.125 & 0.331 & $* *$ & 0.065 & 0.247 & 0.092 & 0.290 & ** \\
\hline \multicolumn{13}{|l|}{ Panel B: Students, household characteristics } \\
\hline Age & 15.889 & 1.104 & 15.745 & 1.121 & 15.918 & 1.092 & $*$ & 16.379 & 1.335 & 16.500 & 1.393 & \\
\hline Form 3 & 0.799 & 0.401 & 0.739 & 0.440 & 0.746 & 0.436 & $*$ & 0.782 & 0.413 & 0.770 & 0.421 & \\
\hline Number of adults in the household & 2.899 & 1.618 & 3.193 & 1.822 & 3.105 & 1.748 & & 3.296 & 1.924 & 3.298 & 1.840 & \\
\hline Number of children under age 6 & 0.976 & 1.027 & 0.896 & 0.981 & 1.047 & 0.986 & *** & 0.987 & 1.112 & 1.049 & 1.055 & \\
\hline Lost a father or mother (1=yes) & 0.346 & 0.476 & 0.185 & 0.388 & 0.209 & 0.407 & *** & 0.294 & 0.456 & 0.230 & 0.421 & ** \\
\hline Household head (1=female) & 0.388 & 0.488 & 0.271 & 0.445 & 0.255 & 0.436 & ** & 0.299 & 0.458 & 0.232 & 0.422 & ** \\
\hline Female head/spouse can read/write in English (1=yes) & 0.162 & 0.369 & 0.239 & 0.426 & 0.166 & 0.372 & * & 0.185 & 0.388 & 0.169 & 0.375 & \\
\hline Child earns money for the household (1=yes) & 0.398 & 0.490 & 0.309 & 0.462 & 0.350 & 0.477 & $*$ & 0.537 & 0.499 & 0.539 & 0.499 & \\
\hline Food security (1=always have enough food) & 0.350 & 0.477 & 0.541 & 0.499 & 0.438 & 0.496 & $*$ & 0.421 & 0.494 & 0.358 & 0.480 & $* *$ \\
\hline Distance to school (more than 2 hours) & 0.194 & 0.395 & 0.204 & 0.403 & 0.185 & 0.389 & & 0.211 & 0.408 & 0.190 & 0.392 & \\
\hline Cost of schooling ( $1=$ Parents cannot afford $)$ & 0.578 & 0.494 & 0.385 & 0.487 & 0.408 & 0.492 & $* *$ & 0.437 & 0.496 & 0.415 & 0.493 & \\
\hline Asset index (based on ownership of 7 assets) & -0.229 & 0.635 & 0.150 & 0.688 & 0.129 & 0.652 & $* *$ & -0.047 & 0.779 & 0.085 & 0.768 & ** \\
\hline \# districts & 6 & & 6 & & 4 & & & 6 & & 4 & & \\
\hline \# schools & 81 & & 81 & & 60 & & & 81 & & 60 & & \\
\hline $\mathrm{N}$ & 1,555 & & 1,003 & & 1,558 & & & 2,325 & & 1,307 & & \\
\hline
\end{tabular}

Notes: Financial support is only received by the most marginalised girls. Other support is received by boys and girls in CAMFED-supported schools and in control schools. Asterisks *,** indicated statistical differences between samples at $5 \& 1 \%$ level, respectively. For the sub-sample of girls, statistical differences are between three groups whereas for boys it is only between those in CAMFED-supported schools and those in control schools. There are no statistical differences in baseline scores in Maths and English between girls (and boys) in CAMFED-Supported schools and those in control schools. 
Table 3: Impact of CAMFED's interventions on English and Maths tests scores (standard deviations) and likelihood to dropout (odds ratio)

\begin{tabular}{|c|c|c|c|c|c|}
\hline & $\begin{array}{r}\text { Sample Size } \\
\text { (1 to } 1 \text { matched })\end{array}$ & $\begin{array}{r}\text { Maths }^{(1)} \\
\text { (SD) }\end{array}$ & $\begin{array}{r}\text { English }^{(1)} \\
(\mathrm{SD})\end{array}$ & $\begin{array}{r}\text { Combined } \\
\text { (SD) }\end{array}$ & $\begin{array}{r}\text { Dropout }^{(2)} \\
(\mathrm{OR})\end{array}$ \\
\hline $\begin{array}{l}\text { Girls receiving } \\
\text { financial support } \\
\text { (relative to matched } \\
\text { sample) }\end{array}$ & 2,108 & $1.189 * *$ & $0.589 * *$ & $0.889 * *$ & $0.75^{* *}$ \\
\hline $\begin{array}{l}\text { Other girls receiving } \\
\text { all other support } \\
\text { (relative to matched } \\
\text { sample) }\end{array}$ & 1,704 & $1.195 * *$ & $0.602 * *$ & $0.898 * *$ & 1.120 \\
\hline $\begin{array}{l}\text { Boys receiving all } \\
\text { other support (relative } \\
\text { to matched sample) }\end{array}$ & 2,376 & $0.657 * *$ & $0.436 * *$ & $0.546 * *$ & 0.826 \\
\hline
\end{tabular}

Notes: (1) Maths and English test scores are presented in standard deviations (SD). Estimates parameters are the difference-in-differences based on 1 to 1 matched samples and obtained from multiple imputation methods to condition out cohort composition effects, area fixed effects. Standard errors are corrected for clustering at school level. (2) Likelihood of dropout is based on a logit model estimated using the 1 to 1 matched samples, controlling for area fixed effects. Results for dropout changes are presented as odds ratio (OR) and standard errors adjusted for clustering at school level. Asterisks *,** indicate statistical significance at 5 and $1 \%$ level, respectively. 
Table 4. Cost-effectiveness analysis (in current US\$), per year for English

\begin{tabular}{lc|c|c}
\hline & $\begin{array}{c}\text { CER (cost per } \\
\text { additional SD) }\end{array}$ & $\begin{array}{c}\text { Additional SD per } \\
\$ 100\end{array}$ & $\begin{array}{c}\text { Additional Years of } \\
\text { Schooling per \$100 }\end{array}$ \\
\hline Group & $\begin{array}{c}\text { English } \\
\text { USD }\end{array}$ & $\begin{array}{c}\text { English } \\
\text { SD }\end{array}$ & $\begin{array}{c}\text { English } \\
\text { Years }\end{array}$ \\
\hline Girls supported financially & $\$ 443$ & 0.23 & 0.43 \\
Other girls supported & $\$ 51$ & 1.96 & 3.76 \\
Other boys supported & $\$ 71$ & 1.42 & 2.72 \\
\hline Weighted CER & $\$ 133$ & 0.75 & 1.45 \\
\hline
\end{tabular}

(1) The weighted cost-effectiveness ratio is obtained from formula 1. 
Table 5: Weighted Cost-effectiveness for Access and Learning (All Girls and Boys)

\begin{tabular}{crrr}
\hline & $\begin{array}{c}\text { Cost- } \\
\text { effectiveness } \\
\text { ratio (cost per } \\
\text { additional SD) }\end{array}$ & $\begin{array}{c}\text { Additional SD } \\
\text { per \$100 }\end{array}$ & $\begin{array}{r}\text { Additional Years } \\
\text { of Schooling per } \\
\$ 100\end{array}$ \\
\hline & $\begin{array}{r}\text { English } \\
\text { USD }\end{array}$ & $\begin{array}{r}\text { English } \\
\text { SD }\end{array}$ & $\begin{array}{r}\text { English } \\
\text { Years }\end{array}$ \\
\hline $\begin{array}{c}\text { Ignoring reductions in } \\
\text { dropout (equation 1) }\end{array}$ & $\$ 133$ & & \\
$\begin{array}{c}\text { Including reductions in } \\
\text { dropout (equation 2) }\end{array}$ & $\$ 92$ & 0.75 & 1.45 \\
\hline $\begin{array}{c}\text { Absolute change } \\
\text { Relative change }\end{array}$ & -41 & 1.09 & 2.10 \\
\hline
\end{tabular}


Figure 1. Propensity Score for those in treatment vs control, financial support and other support by gender

Panel A: Girls Financial Support



Panel B: Girls Other Support

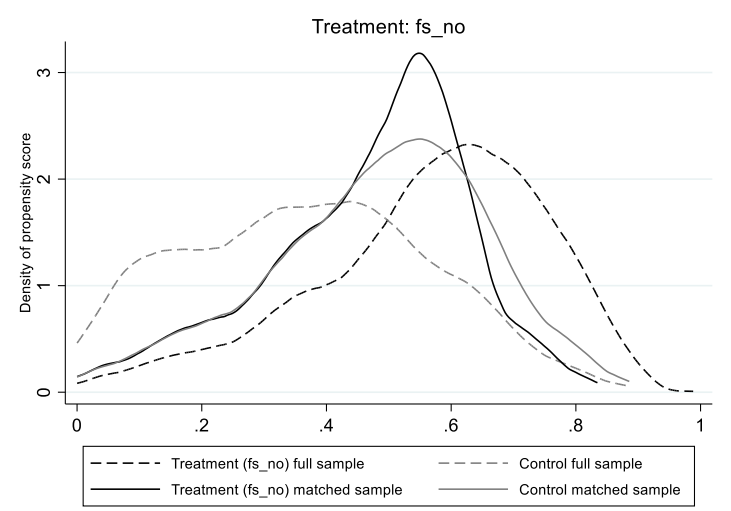

Panel C: Boys Other Support

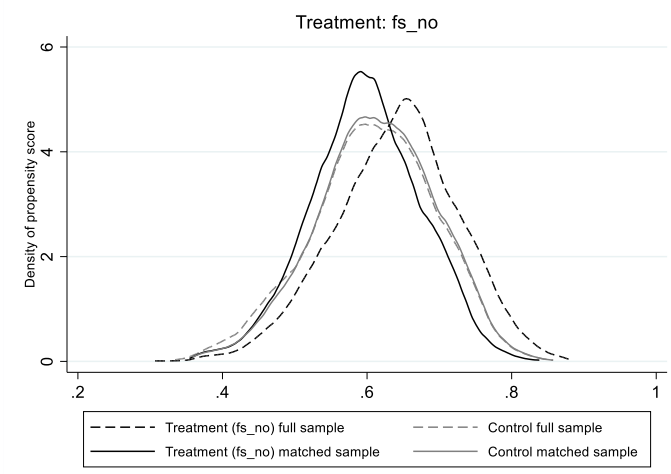


Figure 2: Comparison of the cost-effectiveness of CAMFED's programme with other related educational interventions in sub-Saharan Africa

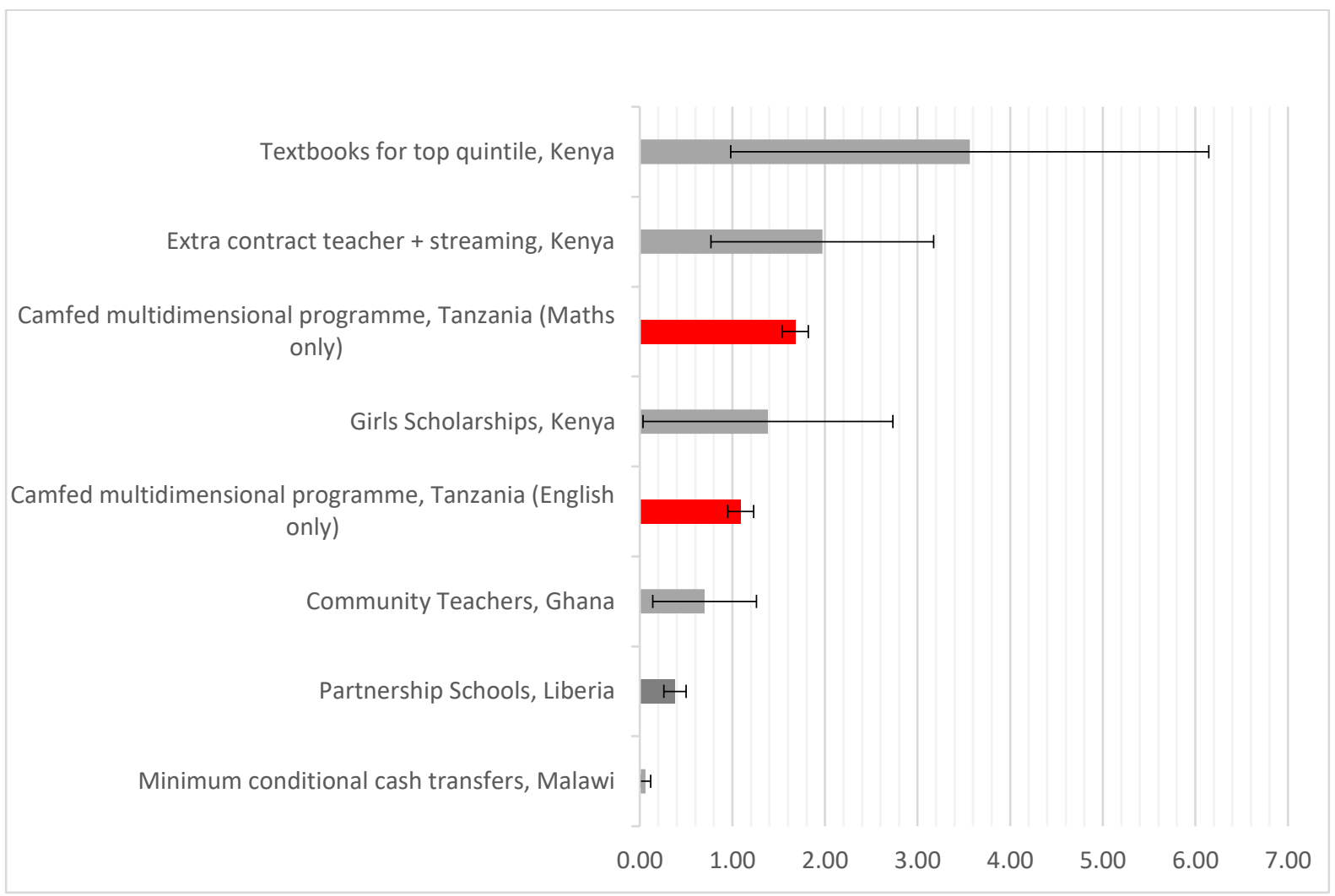

Notes: Unit of measure 'Additional standard deviation per \$100'. Weighted cost effectiveness for CAMFED are obtained using Formula 2. Sources: Calculations for for Malawi and Kenya: J-PAL (2014); Ghana: Kiessel and Duflo (2014) ${ }^{\mathrm{xvi}}$ : Liberia: Romero, Sandefur and Sandhotz (2017). 
${ }^{\mathrm{i}}$ Data from the World Inequality Database on Education (WIDE): https://www.education-inequalities.org/

${ }^{\text {ii }}$ See https://www.gov.uk/guidance/girls-education-challenge

iii For a review of cost effectiveness analysis see, for instance, Dhaliwal et al. (2013); McEwan (2012, 2015).

${ }^{\text {iv }}$ For further information about the allocation and distribution of costs for CAMFED's programme, see Delprato et al. (2017).

${ }^{v}$ See https://www.povertyactionlab.org/research-resources/cost-effectiveness

vi Until the abolition of secondary school fees in Tanzania in 2016, CAMFED's direct financial support covered the costs for supported girls related to school fees and examination fees, lodging for some of them and other items (e.g. costs associated with a bed, blanket, mattress, sanitary wear, shoes, and clothes). In this paper, we utilise the costs which affected the CAMFED intervention at the time (i.e. those including schools and examination fees).

vii Available at https://www.povertyactionlab.org/research-resources/cost-effectiveness

viii The adjusted exchange rate at the time was US $\$ 1.56$ per GBP.

ix Control schools were selected with the agreement of the evaluation manager of the Girls' Education Challenge, taking account of schools with similar education characteristics at the baseline. For example, before the intervention, for the control group in Dodoma districts the average pass rate in the Form 4 secondary school examination was 39\% and 27\%, comparable to the pass rates in CAMFED-supported districts such as Iringa (47\%) and Morogoro (23\%). The districts of Pwani in the control group also showed similar pass rates $(21 \%$ and 16\%) compared with districts supported by CAMFED in Pwani (with a pass rate of $21 \%$ ) and Tanga (21\% and 9\%). For further information, see CAMFED International (2015).

${ }^{x}$ Unfortunately, we only have the overall score from the test that was provided by the Tanzanian Examinations Authority to CAMFED. Without individual items, we are unable to generate a scale which would provide more detailed information on competencies achieved.

${ }^{x i}$ We do not have data over time at the school level to be able to provide a visual representation of the parallel trend assumption. Hence, we remain cautious with the claim that this assumption is met.

xii As will be seen in the discussion on the calculation of additional years of schooling, it is not meaningful to derive an estimate for mathematics if there is no, or almost no, learning gains in the control group.

xiii To do this, the CER is standardised to $\$ 100$ and the corresponding standard deviation modified accordingly.

xiv In Romero, et al. (2017)'s study, the effect on English test scores of being randomly assigned to the programme after one academic year of treatment was .18 of a standard deviation and the average increase in test scores for each additional year of schooling in the control group was .31 of a standard deviation. This information was used to transform the effect into an equivalent of roughly 0.56 additional years of schooling for English $(.18 s / .31 s)$. This approach adjusts the standard deviation according to the grade since we are using a dispersion measure from the control group for the same grades over the same time period. However, we are assuming that this dispersion measure stays constant over time if the equivalent years of school estimate goes beyond a year and it is projected over a longer time horizon.

${ }^{x v}$ Without the data from the Kenya project we are unable to test this, but the fact that the confidence intervals overlap provide an initial evidence for the rejection of the alternative hypothesis (which indicates that the Kenya scholarship programme provides a more cost effective way to improve learning than the CAMFED programme). ${ }^{x v i}$ Confidence intervals were estimated from the results presented in the working paper available at: https://www.theigc.org/wp-content/uploads/2014/10/Duflo-Kiessel-2012-Working-Paper.pdf. 